\title{
Evaluation of real-time satellite rainfall products in semi-arid/arid Australia
}

\author{
$\underline{\text { R. C. Pipunic }}{ }^{1}$, D. Ryu ${ }^{1}$, J. Costelloe ${ }^{1}$ and C-H. Su ${ }^{1}$ \\ Affiliations: ' Department of Infrastructure Engineering, The University of Melbourne, Parkville, Vic. 3010 \\ (Email: robp@unimelb.edu.au)
}

\begin{abstract}
The quality of runoff/streamflow modelling is critically dependent on the quality of rainfall forcing data and a quantitative understanding of its uncertainty. More accurate rainfall data with clearly defined uncertainty has implications for water resource management and flood prediction. This is important for the Lake Eyre Basin (LEB) in central Australia where the landscape is very flat and hydrophobic soils are common. The LEB is also of interest in terms of climate given that it is predominantly semi-arid/arid with a large north-south rainfall gradient. The north is subject to intense tropical (summer-time) based rainfall events, with weaker predominantly winter rainfall occurring in the south where annual totals are approximately 3-4 times lower on average than in the north. The remoteness of this region means that the insitu rainfall observation network is sparse compared to more densely populated regions across Australia's eastern seaboard, hence the potential of remotely sensed spatial rainfall data to provide useful information here needs to be examined. Three real-time satellite precipitation products, the TRMM Multi-satellite Precipitation Analysis 3B42RT (TRMM-RT) Version 7, CPC Morphed precipitation (CMORPH) Version 1, and Precipitation Estimation from Remote Sensing Information using Artificial Neural Network (PERSIANN), are assessed against in-situ rain gauge data over a nine-year study period to examine characteristics of their error in LEB. An up-scaled version of the Australian Water Availability Project (AWAP) spatial rainfall product (interpolated from gauge data) was also assessed against the same gauge data used for the satellite products, as a benchmark for comparing the satellite product assessments. All data were mapped to a $0.25^{\circ}$ resolution grid and aggregated to daily time step rainfall totals (9am to 9am), with errors calculated as differences in daily rainfall between the products and gauge data for the nine-years. Products were assessed by inter-comparing the distribution of their daily errors via boxplots, and through bias (average error) and root mean square differences (RMSD) over the nine-years. The ability of satellite products to detect rain gauge measured events was also examined via calculation of the Probability of Detection (POD) and False Alarm Ratio (FAR) metrics.
\end{abstract}

Based on error distributions for each rainfall product over the full nine-years, TRMM-RT is the closest match to gauge observations of the three satellite products. Its mean bias is $\sim 0.3 \mathrm{~mm} /$ day, approximately 3.5 and 4.5 times less than that of CMORPH and PERSIANN respectively, while the unbiased Root Mean Square Difference (RMSD) of $\sim 4.3 \mathrm{~mm} /$ day for TRMM-RT is less than half that for both CMORPH and PERSIANN. Comparisons of product error distributions show consistently lower variation and less extreme outlier values occurring for TRMM-RT error. In addition, while the median TRMM-RT error displays a trend of increasing negative bias with increasing rainfall totals, the median CMORPH and PERSIANN errors show the opposite and steeper trend. Common amongst all of the products is an increase in absolute error ranges with increasing daily rainfall totals, in addition to absolute errors calculated over wet season months (mostly summer) having a generally larger spread than over dry season months (mostly winter) in the basin's tropical north. The results provide insights into how error for a product such as TRMM-RT may be best modelled. There are a number of extreme errors in all products, shown as outliers in boxplots, and mostly implying large over-estimates of rainfall. By defining extreme outlier error values as $>20 \mathrm{~mm} /$ day and/or $>100 \%$ of gauge values, a sample of these were found to occur at or near the edge of major rainfall systems as delineated by the TRMM-RT products, indicating they may be an artifact of spatial inaccuracy in resolving the edges of rainfall extents, warranting further study. POD and FAR metrics for TRMM-RT further demonstrated differences in performance across ranges of daily rainfall totals, and between tropical wet and dry seasons in the LEB. POD results show there is generally greater chance of detecting the presence of larger rainfall accumulations. From FAR statistics, false alarms are generally more prevalent amongst smaller TRMM-RT estimates and in dry seasons, where FAR values decrease in relation to increasing average TRMM-RT estimates.

Keywords: $\quad$ Rainfall, remote sensing, rain gauges, error estimation. 


\section{INTRODUCTION}

The accuracy of water/energy exchanges at the land surface and runoff/streamflow modelling is critically dependent on the quality of rainfall forcing data, and a quantitative uncertainty of it comprises one of the major components of overall uncertainty in hydrological predictions. More accurate rainfall data and improved runoff/streamflow modelling with clearly defined uncertainty has important implications for water resource management and flood prediction. This is particularly relevant for the arid landscape of the Lake Eyre Basin (LEB) in central Australia which experiences very high inter-annual variability in streamflow, partly driven by intense rainfall originating from northern tropical systems (McMahon et al., 2005). Despite being sparsely populated, LEB contains a number of commercial mining and natural resource interests with large areas used for grazing. Therefore, better runoff and flood forecasting capabilities are becoming more important here.

There are a number of spatially distributed rainfall data products that provide potential value for use in hydrological modelling. Specific to Australia is the Australian Water Availability Project (AWAP) gridded product based on the interpolation of rain gauge data across the continent (Jones et al., 2009). In addition, a number of datasets derived from satellite remote sensing are available with coverage over most of Australia including LEB. Different rainfall products, based on different information sources and production methodologies, may have their own intrinsic value that can contribute to representing true spatial rainfall (e.g. Pena-Arancibia et al., 2013). Due to its remoteness, in-situ rain gauge coverage over the LEB is relatively sparse (compared to more populated parts of Australia) and may not be able to adequately represent rainfall from spatially restricted convective systems. The potential of satellite-based rainfall to contribute to improved rainfall representation over gauge sparse regions in Australia is demonstrated by Chappell et al. (2013). In this regard, satellite products may have some advantages, highlighting the need to consult different information sources towards a best estimate of rainfall spatio-temporal coverage.

Three prominent real-time satellite precipitation products examined here (Table 1) include the TRMM Multisatellite Precipitation Analysis 3B42RT (TRMM-RT) Version 7, CPC Morphed precipitation (CMORPH) Version 1, and Precipitation Estimation from Remote Sensing Information using Artificial Neural Network (PERSIANN). Examining TRMM Version 7 data here is important given it has only been scrutinised in a few studies (e.g. Chen et al., 2013) as opposed to the other products. A number of past studies have investigated the validation of these satellite products (including earlier versions of TRMM), such as Ebert $e t$ al. (2007) for continental U.S., Australia and Europe, Behrangi et al. (2011) over the Illinois river basin, and Gao and Liu (2012) over the high altitude Tibetan Plateau with contrasting microclimates. Findings from these studies highlight that while such products provide valuable information, various shortcomings exist with their performance depending on a range of factors. These include rainfall regime, season, latitude, humidity, topographical terrain and difficulty with light rain from shallow clouds. Also, bias in these products was shown to be an important factor impacting streamflow prediction quality in hydrologic modelling (e.g. Behrangi et al., 2012). Thus, further validation work of real-time satellite precipitation products is essential, especially for a wider range of contrasting environments and climate regimes, such as those in the LEB, in order to realize their full potential for hydrological applications.

The gridded AWAP product is based predominantly on direct daily gauge measurements for which uncertainty can be reasonably well quantified. A potential downside is that the quality of interpolated information between gauge locations may vary, and the uncertainty may increase over poorly gauged and/or climatologically heterogeneous regions such as the LEB. There is also potential for errors introduced by the interpolation routine, even across gauge-dense areas. Satellite observations provide sub-daily rainfall accumulation estimates but they can be erroneous due to spatiotemporal sampling, instrument and algorithm errors (Gebremichael et al., 2005). Overall, there may be some areas where remotely sensed data are more reliable than gauge-interpolated AWAP or vice-versa. Towards identifying and drawing upon the best available information from different spatial rainfall datasets, error assessments of the different datasets need to be conducted. This study assesses the aforementioned three remotely sensed gridded rainfall products against available in-situ rain gauge data across the LEB, with AWAP assessment included as a benchmark. The evaluation is performed via visual examination of error distributions, and using the mean bias, Root Mean Square Difference (RMSD), Probability of Detection (POD) and False Alarm ratio (FAR) of errors. Rainfall error information from this assessment provides valuable information for ongoing efforts to improve hydrologic prediction across this Basin. 
Pipunic et al., Evaluation of real-time satellite rainfall products in semi-arid/arid Australia

\section{DATASETS AND ANALYSIS}

\subsection{Lake Eyre Basin (LEB)}

McMahon et al. (2005) describe the LEB in central Australia as a semi-arid to arid internally drained system, draining an area of $\sim 1,140,000 \mathrm{~km}^{2}$. In terms of topography, a major control on rainfall surface runoff, they describe the maximum elevation of most headwaters of LEB catchments as being between $300-400 \mathrm{~m}$ and the gradient in the mid to lower reaches of some of the major catchments are said to be in the order of $10^{-4} \mathrm{~m} / \mathrm{m}-$ hence a generally flat landscape.

LEB comprises large parts of northeast South Australia, the southeast of the Northern Territory, southwest Queensland and a small portion of northwest New South Wales. A subtropical high-pressure ridge across central Australia is a strong synoptic feature over the LEB, with annual average rainfall ranging from $\sim 500$ $\mathrm{mm}$ in the north, which is dominated by summer rainfall, down to $\sim 150 \mathrm{~mm}$ through the centre and south of the basin where weaker winter rainfall dominates (McMahon et al., 2005). Monsoonal activity, tropical depressions and cut-off low-pressure systems are the cause of most flood events in the LEB (McMahon et al., 2005).

\subsection{Rainfall Products}

Pertinent specifications of the three remotely sensed data products assessed over the LEB for this study TRMM-RT, CMORPH and PERSIANN - are summarised in Table 1, together with the AWAP analyses and gauge data used.

Table 1: Rainfall datasets used for the analyses.

\begin{tabular}{|c|c|c|c|c|c|}
\hline Dataset & $\begin{array}{l}\text { Managing } \\
\text { Institution }\end{array}$ & Measurement Basis & Version & $\begin{array}{c}\text { Spatial } \\
\text { Resolution }\end{array}$ & $\begin{array}{c}\text { Temporal } \\
\text { Resolution }\end{array}$ \\
\hline $\begin{array}{l}\text { TRMM } \\
\text { 3B42RT } \\
\text { (TRMM-RT) }\end{array}$ & $\begin{array}{l}\text { NASA and the Japan } \\
\text { Aerospace Exploration } \\
\text { Agency (JAXA) }\end{array}$ & $\begin{array}{c}\text { Precipitation radar, } \\
\text { microwave, visible, infra-red, } \\
\text { cloud, radiant energy and } \\
\text { lightning sensors. } \\
\text { (Huffman et al., 2007) }\end{array}$ & 7 & $0.25^{\circ}$ & 3-hourly \\
\hline CMORPH & $\begin{array}{l}\text { National Oceanic and } \\
\text { Atmospheric } \\
\text { Administration } \\
\text { (NOAA) }\end{array}$ & $\begin{array}{c}\text { Passive polar microwave and } \\
\text { geostationary infra-red } \\
\text { sensors } \\
\text { (Joyce et al., 2004) }\end{array}$ & 1.0 & $0.25^{\circ}$ & 3-hourly \\
\hline PERSIANN & $\begin{array}{c}\text { Centre for } \\
\text { Hydrometeorology \& } \\
\text { Remote Sensing, } \\
\text { University of } \\
\text { California, Irvine }\end{array}$ & $\begin{array}{l}\text { Geostationary infra-red and } \\
\text { visible } \\
\text { (Sorooshian et al., 2000) }\end{array}$ & $\begin{array}{l}\text { Downloaded on } \\
10 \text { May } 2013\end{array}$ & $0.25^{\circ}$ & 3-hourly \\
\hline AWAP & $\begin{array}{l}\text { Australian Bureau of } \\
\text { Meteorology (BoM) }\end{array}$ & $\begin{array}{l}\text { Grid surface from spline- } \\
\text { based interpolation of BoM } \\
\text { point scale gauge data } \\
\text { (Jones et al., 2009) }\end{array}$ & Operational & $0.05^{\circ}$ & $\begin{array}{c}\text { Daily (9am to } \\
\text { 9am) }\end{array}$ \\
\hline $\begin{array}{l}\text { GAUGE } \\
\text { DATA }\end{array}$ & $\begin{array}{l}\text { Australian Bureau of } \\
\text { Meteorology (BoM) }\end{array}$ & & $\begin{array}{c}\text { Processed - BoM } \\
\text { quality checked }\end{array}$ & $\begin{array}{l}\text { Point (in-situ } \\
\text { station) }\end{array}$ & $\begin{array}{c}\text { Daily (9am to } \\
\text { 9am) }\end{array}$ \\
\hline
\end{tabular}

To enable direct inter-comparisons, all data were processed to uniform spatial and temporal resolution as per the coarsest scale datasets for both of these domains - being $0.25^{\circ}$ pixel size as per remotely sensed products, and daily total rainfall over each 24 hour period from 9am to 9am as per gauge data (and therefore AWAP). AWAP was spatially averaged from $0.05^{\circ}$ pixel resolution to $0.25^{\circ}$ and its sole purpose was as a comparative benchmark for the satellite products, as opposed to being evaluated itself. All data were processed for a nineyear time span from January $2^{\text {nd }} 2001$ to $31^{\text {st }}$ December 2009 (3,286 days), which is equal to the maximum period for which all the data available to us at the time of this analysis intersects. While the $1^{\text {st }}$ January 2001 data were omitted as the TRMM-RT data were only available from midnight to 9am.

Gauge data were initially filtered by selecting only gauges with the strictest quality flag - for which data were direct measurements, with no gap filling using alternate observations or modelled information. Processing rain gauge data onto a $0.25^{\circ}$ resolution grid involved assigning to each grid pixel the average value of rain totals from all gauges collocated within it. However this was conditional on: i) The pixel containing a minimum of 2 gauges; and, ii) For each pixel that contained 2 or more gauges, theses gauges had to have valid data entries for a minimum of $70 \%$ of the days across the 3,286 day experiment period. A total of twenty-four $0.25^{\circ} \mathrm{x} 0.25^{\circ}$ pixels satisfied these criteria across the LEB. 


\subsection{Rainfall Analysis}

Exploratory analysis for assessing the rainfall product errors relative to gauge data for the eligible pixels identified in LEB was conducted by calculating mean daily bias, RMSD, POD and FAR metrics. With the exception of FAR the analyses were performed for six separate bin ranges of daily rain gauge totals: $0 \mathrm{~mm}, 0$ $5 \mathrm{~mm}, 5-10 \mathrm{~mm}, 10-20 \mathrm{~mm}, 20-50 \mathrm{~mm}$ and $>50 \mathrm{~mm}$. This series of ranges gives a good indication of how error varies with different rainfall intensity, which is important for future work on runoff modelling. Since there is a tropical influence on the climate of LEB (McMahon et al., 2005), in addition to assessing rainfall products for each day of the nine-year experiment period, two additional assessments were made: i) For all days within tropical wet seasons of the nine-years - defined as spanning the months October through to March; and ii) For all days within tropical dry seasons of the nine-years - defined as spanning April through to September.

Product errors are defined as daily differences, calculated as the product minus the gauge data values for each day across each of the twenty-four analysis pixels. In addition to the metrics listed above, the bias-adjusted RMSD was also determined (calculated after subtracting the bias value from each daily difference value). The POD metric summarises the success of a data product in detecting the presence of gauge-observed rain for each analysis pixel over the series of daily analysis data, excluding days where both the product and gauge values are zero (termed "correct rejections"), calculated as the number rainfall events detected as a fraction of the total number of gauge rainfall events over a given time period. While FAR summarises the tendency of a data product to incorrectly detect the presence of gauge observed rain when there was none (i.e. for gauge readings of $0 \mathrm{~mm}$ ). As with POD, days with correct rejections are not included in the calculation of FAR - it is the total of non-zero product records coinciding with rain gauge measurements of zero for a given time, as a fraction of all rain events in the product series.

\section{RESULTS AND DISCUSSION}

A summary of daily product minus gauge data differences over the full nine-year study period for all LEB gauge pixels is shown in Table 2, from which TRMM-RT clearly has the lowest overall bias and RMSD of the satellite products. Also the overall full data range bias shown here has minimal impact on the RMSD when compared with bias-adjusted RMSD, while for the six bin ranges of rain totals detailed in Section 2.3 the bias increases with the size of the bin range totals and has a slightly greater impact on RMSD (not shown here).

Table 2: Summary statistics for daily rainfall differences between satellite products and gauge data.

\begin{tabular}{|l|c|c|c|c|}
\hline \multicolumn{1}{|c|}{ Error (mm/day) } & TRMM-RT & CMORPH & PERSIANN & AWAP \\
\hline Bias & 0.3 & 1.1 & 1.4 & 0.02 \\
\hline RMSD & 4.4 & 9.0 & 10.0 & 1.1 \\
\hline Bias-adjusted RMSD & 4.3 & 8.9 & 9.9 & 1.1 \\
\hline
\end{tabular}

A series of boxplots in Figure 1 show the spread of daily differences between each rainfall product and gauge data, with separate plots for the different gauge rainfall bin ranges (see description in Section 2.3). The boxes in Figure 1 indicate the $25^{\text {th }}$ and $75^{\text {th }}$ percentiles defining the interquartile range (IQR) of the data around the median (red line), while the extent of the whiskers represent a value of 1.5xIQR beyond the IQR box, and values beyond the whiskers (red circles) indicating outliers. The interquartile range and extent of outliers for the TRMM-RT differences confirm it is clearly the best of the remotely sensed rainfall data products. Furthermore, a comparison between product and gauge differences for both tropical wet and dry seasons (boxplots not shown here) indicates that differences are noticeably greater over tropical wet seasons for all six bin ranges examined, with the magnitude of differences displayed in Figure 1 closely resembling that for the wet season periods. The dry season boxplots have noticeably smaller interquartile ranges and less extreme outliers in general across all six bin ranges. As noted in the introduction, the quality of rainfall product estimates varies as a result of many factors including the rainfall regime and season. So the difference in errors for the tropical seasons here indicates the larger more intense tropical wet season rain events are generally more error prone. A comparison of the products by Romilly and Gebremichael (2011) (they used TRMM 3B42RT Version 6 data) also concluded that factors such as rainfall regime can affect product errors, while they also note that TRMM-RT was generally one of the better performing products.

Boxplot outliers in Figure 1 appear prominent for each satellite product, particularly for smaller bin ranges. The percentage of boxplot outliers per the full sample of daily data differences in each rainfall bin range, for CMORPH, PERSAINN and TRMM-RT respectively is as follows: $10 \%, 9 \%$ and $5 \%$ for gauges $=0 \mathrm{~mm}$; 
$13 \%, 16 \%$ and $12 \%$ for gauges $=0-5 \mathrm{~mm} ; 7 \%, 8 \%$ and $6 \%$ for gauges $=5-10 \mathrm{~mm} ; 7 \%, 9 \%$ and $8 \%$ for gauges $=10-20 \mathrm{~mm} ; 5 \%, 6 \%$ and $8 \%$ for gauges $=20-50 \mathrm{~mm}$; and, $4 \%, 3 \%$ and $4 \%$ for gauges $>50 \mathrm{~mm}$. Since some boxplot outliers for smaller rain totals may be relatively small in magnitude and with very narrow IQRs, we examined an alternate definition of extreme errors as being rainfall product error values $>20$ $\mathrm{mm} /$ day and $>100 \%$ of the gauge measurement. A comparison of a sample of extreme errors from this definition with TRMM-RT data showed that they generally occurred at or near the edge of the spatial extents of rain events defined by the product. This implies that these extreme errors might be related to uncertainty in resolving the precise spatial extent/boundary of the rainfall. However a more comprehensive comparison with a large sample size is necessary to draw firmer conclusions than the anecdotal evidence from samples used here.

With TRMM-RT determined as the best performing product, a series of boxplots were generated (Figure 2) covering a wider bin range of rain totals to more closely examine the error relationship of this product as a function of rainfall accumulation. From Figure 2 there is a clear relationship showing that the error range and negative bias for TRMM-RT increases with increasing rainfall totals. Identifying this relationship is very important in the context of quantifying rainfall forcing data error for hydrologic modelling in the LEB, and provides the basis for more detailed future analysis into understanding and quantifying its relationship with predicted runoff error when it is used as forcing.
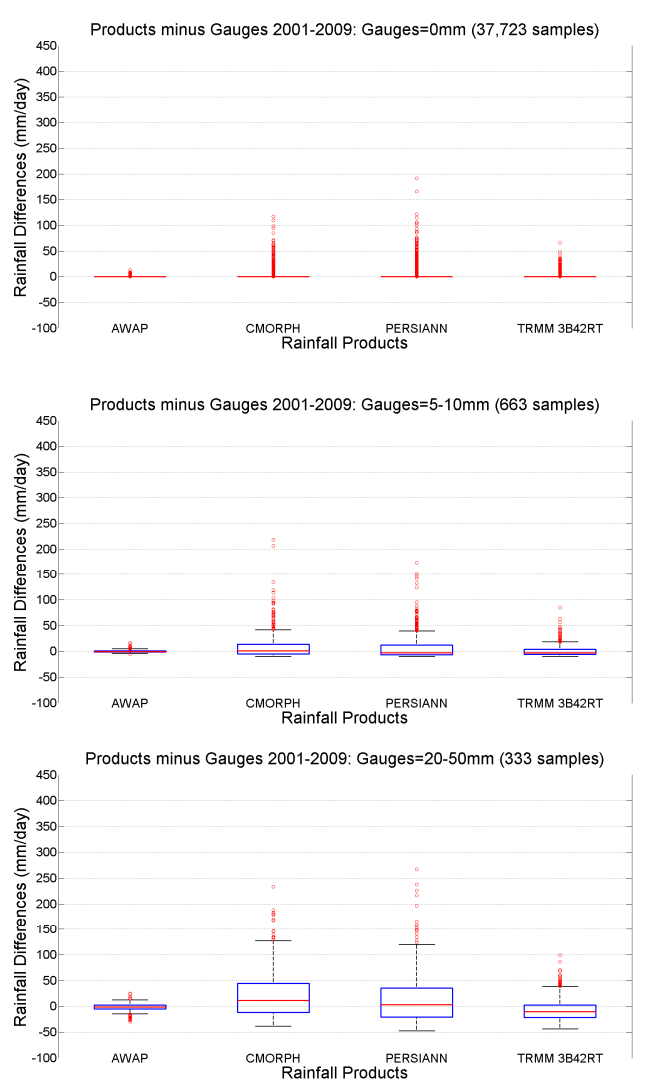
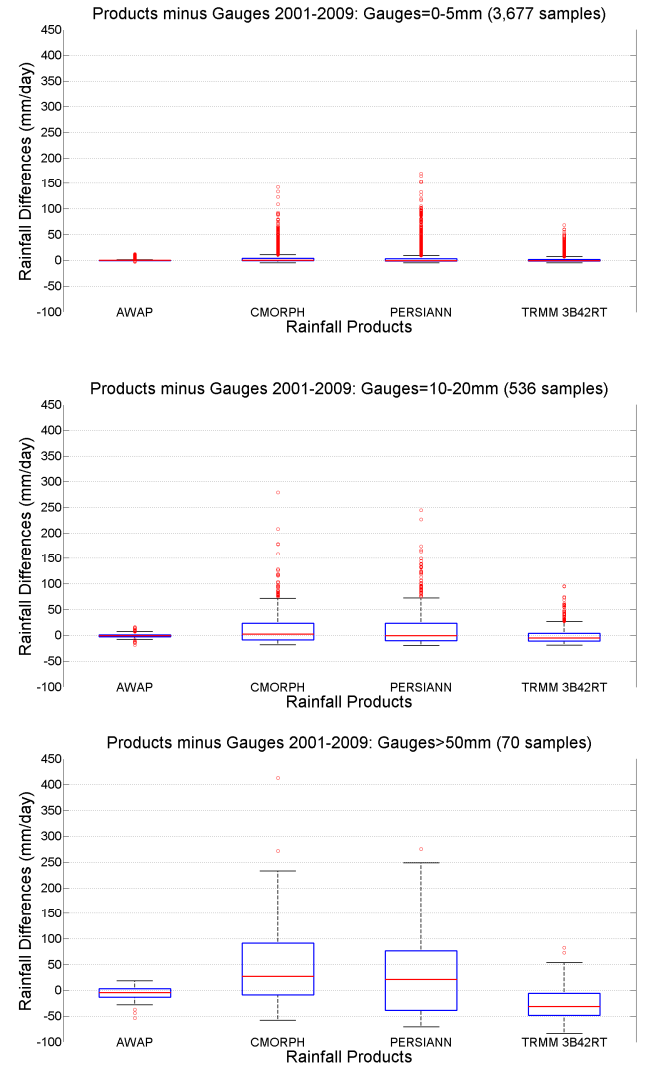

Figure 2: Differences between rainfall products and gauge measurements.

The POD and FAR metrics for TRMM-RT is displayed in Figure 3 a) and b). From 3 a), the pattern of detection per rainfall bin range is generally representative of that for the other remotely sensed products where detection is generally poorer for smaller rainfall amounts. In Figure $3 b$ the FARs of TRMM-RT against average false TRMM-RT estimates show some slight differences between tropical wet and dry season periods (associated months are described in section 2), with ratios generally spread about $\sim 0.4-0.5$ for wet seasons and $\sim 0.5$ for dry seasons. The main difference is that false detections by TRMM-RT are slightly greater in dry seasons and occur with smaller TRMM-RT average values across the twenty-four analysis pixels (from $\sim<$ to $5 \mathrm{~mm} /$ day), with a trend of decreasing ratios with increasing TRMM-RT averages. For 
wet seasons the ratios are spread across larger TRMM-RT averages (from $\sim 3$ to $7 \mathrm{~mm} /$ day) while the relationship is generally flatter with a very slight increasing trend with TRMM-RT averages. Across both seasons the range of most false TRMM-RT values is confined to $\sim<1$ to $7 \mathrm{~mm}$ /day on average. The greater FAR values for dry seasons (winter), and generally low rainfall values, may relate to satellite rainfall estimates typically being better for larger convective rainfall events in summer months (Ebert et al., 2007).

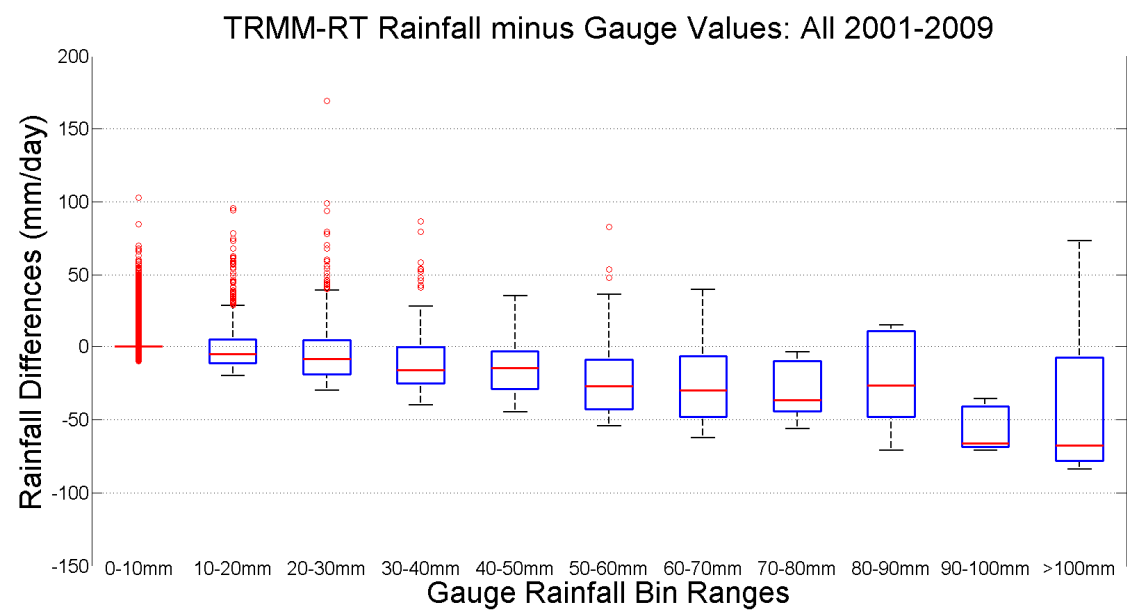

Figure 2: TRMM-RT minus gauge rainfall differences across the LEB for all of 2001-2009, for gauge rainfall bin ranges spanning increments of $10 \mathrm{~mm}$.
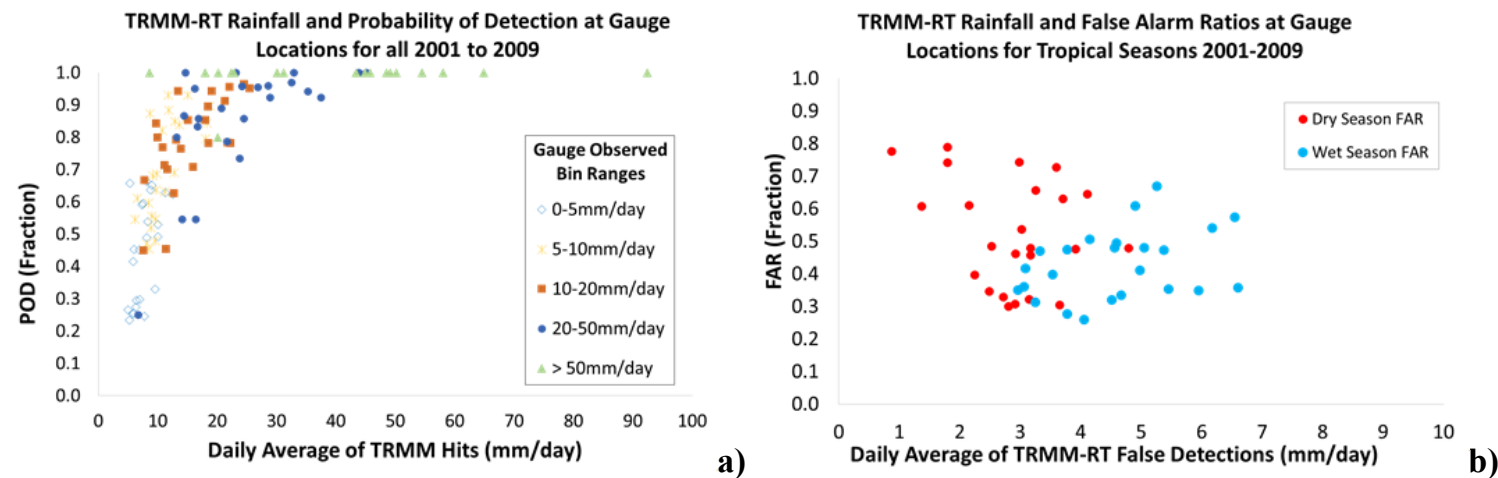

Figure 3: a) POD values for the TRMM-RT product plotted against the daily averaged TRMM-RT Hits used in the calculations; and, b) FAR values for the TRMM-RT product, separated into tropical wet and dry season periods.

\section{CONCLUSIONS}

In general the error in each rainfall product examined increases with greater magnitude rain events. There is greater error in rainfall estimates over tropical wet seasons from all products compared to over dry seasons, which is likely a reflection of the more intense rainfall events from tropical systems.

Of the three satellite products - PERSIANN, CMORPH and TRMM-RT - TRMM-RT was the best with smaller overall daily rainfall errors relative to gauge data for a range of different rainfall bin ranges. Hence this product is most suitable for further investigation into improving rainfall representation over gauge sparse regions such as LEB. Furthermore, the results showed a clear relationship with the daily error in this product as a function of rainfall accumulation - where the error range and the negative bias of the estimates both increase with increasing daily rainfall totals. This is important for predicting rainfall errors in future modelling work and quantifying predicted runoff errors from hydrologic modelling. 
Pipunic et al., Evaluation of real-time satellite rainfall products in semi-arid/arid Australia

Extreme boxplot outliers (defined as beyond 1.5xIQR) appear prominent and make up a larger proportion of total daily rainfall events for smaller rainfall totals. Considering the small IQR for lower rainfall accumulation, some relatively small magnitude errors can be defined as outliers. A small sample of TRMMRT errors, redefined as extreme for being greater than $20 \mathrm{~mm}$ /day and more than double the gauge values, provided anecdotal evidence that some extreme errors are associated with locations at or near the edges of spatial rainfall extents as represented by the product. This could be an indication that there is high uncertainty in resolving the edges of rain events with satellite estimates and warrants more robust examination for a better understanding.

TRMM-RT appears the most suitable satellite rainfall product with the potential to improve rainfall characterisation together with AWAP over more remote areas of Australia, such as the LEB. In contrast to CMORPH and PERSIANN, the errors for AWAP and TRMM-RT are closest for the larger rainfall events, which are of most interest for flood forecasting. There are distinct tropical seasonal differences in the data that need to be more closely examined, along with further assessment relative to AWAP away from rain gauge locations. The latter assessment will provide improved confidence in the whether there is additional value in merging interpolated rainfall data (i.e. AWAP) with a satellite-derived product (i.e. TRMM-RT).

\section{ACKNOWLEDGEMENTS}

This work is supported by the Carlton Connect Initiative Fund for 'Integrated Model-Observation System for Water Resources Assessment in Remote Regions'- a collaborative research project between The University of Melbourne and the South Australian Department of Environment, Water and Natural Resources.

\section{REFERENCES}

Pena-Arancibia, P., A. van Dijk, L.J. Renzullo, and M. Mulligan (2013). Evaluation of precipitation estimation accuracy in reanalyses, satellite products and an ensemble method for regions in Australia and in south and east Asia. Journal of Hydrometeorology. 14, 1323-1333.

Behrangi, A., B. Khakbaz, T.C. Jaw, A. AghaKouchak, K. Hsu, and S. Sorooshian (2011). Hydrologic evaluation of satellite precipitation products over a mid-size basin. Journal of Hydrology. 397, 225-237.

Chappell, A., L.J. Renzullo, T.H. Raupach, and M. Haylock (2013). Evaluating geostatistical methods of blending satellite and gauge data to estimate near real-time daily rainfall for Australia. Journal of Hydrology. 493, 105-114.

Chen, Y., E.E. Ebert, K.J.E. Walsh, and N.E. Davidson (2013). Evaluation of TRMM 3 B42 precipitation estimates of tropical cyclone rainfall using PACRAIN data. Journal of Geophysical Research Atmospheres. 118, 2184-2196.

Ebert, E.E., J.E. Janowiak, and C. Kidd (2007). Comparison of near-real-time precipitation estimates from satellite observations and numerical models. Bulletin of the American Meteorological Society. 88, 1-47.

Gao, Y.C., and M.F. Liu (2012). Evaluation of high-resolution satellite precipitation products using rain gauge observations over Tibetan Plateau. Hydrology and Earth System Science Discussions. 9, 9503-9532.

Gebremichael, M., Krajewski, W. F., Morrissey, M. L., Huffman, G. J., and Alder, R. F. (2005). A detailed evaluation of GPCP 10 daily rainfall estimates over Mississippi River Basin. Journal of Applied Meteorology. 44, 665-681.

Huffman, G. J., R. F. Adler, M. M. Morrisey, D. T. Bolvin, S. Curtin, R. Joyce, B. McGavock, and J. Susskind (2007). The TRMM multisatellite precipitation analysis (TMPA): Quasi-global, multiyear, combined-sensor precipitation estimates at fine sales. Journal of Hydrometeorology. 8, 38-55.

Jones, D.A., W. Wang, and R. Fawcett (2009). High-quality spatial climate data-sets for Australia. Australian Meteorological and Oceanographic Journal. 58, 233-248.

Joyce, R.J., J.E. Janowiak, P.A. Arkin, and P.P. Xie (2004). CMORPH: A method that produces global precipitation estimates from passive microwave and infrared data at high spatial and temporal resolution. Journal of Hydrometeorology. 5, 487-503.

McMahon, T.A., R. Murphy, P. Little, J.F. Costelloe, M.C. Peel, F.H.S. Chiew, S. Hayes, R. Nathan, and D.D. Kandel (2005). Hydrology of Lake Eyre Basin, pp.139. Sinclair Knight Merz Project Report for Department of Environment and Heritage.

Romilly, T. G., and M. Gebremichael (2011). Evaluation of satellite rainfall estimates over Ethiopian river basins. Hydrology and Earth System Sciences. 15, 1505-1514.

Sorooshian, S., K.L. Hsu, X. Gao, H.V. Gupta, B. Imam, and D. Braithwaite (2000). Evaluation of PERSIANN system satellite-based estimates of tropical rainfall. Bulletin of the American Meteorological Society. 81, 2035-2046. 